\title{
Utilization of Pyrosequencing to Monitor the Microbiome Dynamics of Probiotic Treated Poultry (Gallus gallus domesticus) during Downstream Poultry Processing
}

\author{
Vamsy Priya Guttala1, Enrique G. Medrano², Joey Bray¹, Beatrice Clack ${ }^{*}$ \\ ${ }^{1}$ Stephen F. Austin State University, Department of Biology, Nacogdoches, USA \\ ${ }^{2}$ United States Department of Agriculture, Agricultural Research Service, College Station, USA \\ Email: ^bclack@sfasu.edu
}

How to cite this paper: Guttala, V.P., Medrano, E.G., Bray, J. and Clack, B. (2017) Utilization of Pyrosequencing to Monitor the Microbiome Dynamics of Probiotic Treated Poultry (Gallus gallus domesticus) during Downstream Poultry Processing. Agricultural Sciences, 8, 675-691.

https://doi.org/10.4236/as.2017.87051

Received: May 23, 2017

Accepted: July 25, 2017

Published: July 28, 2017

Copyright $\odot 2017$ by authors and Scientific Research Publishing Inc. This work is licensed under the Creative Commons Attribution International License (CC BY 4.0).

http://creativecommons.org/licenses/by/4.0/ (c) (i) Open Access

\begin{abstract}
Antibiotic growth promoters that have been historically employed to control pathogens and increase the rate of animal development for human consumption are currently banned in many countries. Probiotics have been proposed as an alternative to control pathogenic bacteria. Traditional culture methods typically used to monitor probiotic effects on pathogens possess significant limitations such as a lack in sensitivity to detect fastidious and non-culturable bacteria, and are both time consuming and costly. Here, we tested next generation pyrosequencing technology as a streamline and economical method to monitor the effects of a probiotic on microbial communities in juvenile poultry (Gallus gallus domesticus) after exposure to several microbiological challenges and litter conditions. Seven days and repeated again at 39 days following hatching, chicks were challenged with either Salmonella enterica serovar Enteritidis, Campylobacter jejuni, or no bacteria in the presence of, or without a probiotic (i.e., Bacillus subtilis) added to the feed. Three days following each of two challenges (i.e., days 10 and 42 , respectively) the microbiome distributions of the poultry caecum were characterized based on $16 \mathrm{~S}$ rDNA analysis. Generated PCR products were analyzed by automated identification of the samples after pooling, multiplexing and sequencing. A bioinformatics pipeline was then employed to identify microbial distributions at the phylum and genus level for the treatments. In conclusion, our results demonstrated that pyrosequencing technology is a rapid, efficient and cost-effective method to monitor the effects of probiotics on the microbiome of poultry propagated in an agricultural setting.
\end{abstract}

\section{Keywords}

Poultry Production, Probiotics, Pyrosequencing, Mutiplex Identifier (MID), 
Microbiota

\section{Introduction}

Since 1995, the Poultry industry has become one of the globes' largest and fastest growing segments of animal food production [1]. The United States is one of the largest producers of poultry with the broiler sector playing a major role [2]. Crowded poultry housing conditions are stressful to the birds leading to an elevated disease potential. Additionally, packed houses cause deterioration of environmental conditions providing a situation that is conducive to the spread of disease and thus increase the possibility of transmission to humans [3]. Outbreaks of campylobacteriosis and salmonellosis infections due to the consumption of contaminated poultry or derived products have occurred in human populations throughout the world and are thus a major concern [4] [5] [6] [7] [8].

Antimicrobial growth promoters (AGPs) consist of antibiotics that are added to the feed of animals to enhance their growth rate and production performance [9]. Unfortunately, the large quantities of AGPs that have been used in poultry production provided a source for development of antibiotic resistant bacteria [10]. For example, Campylobacter was found to be increasingly resistant to antibiotics such as fluoroquinolones and macrolides that are used as antimicrobials for the treatment of campylobacteriosis [11]. Additionally, the development of resistance to antibiotics by Salmonella has also been reported [12]. Hence, there is an increased necessity not only to minimize AGP use but also to develop novel non-antibiotic-based alternative treatments. Probiotics are being considered to fill this gap with utilization in certain farms instead of antibiotics [13] [14]. The most common probiotic additives used in the broiler industry include Aspergillus, Bacillus, Bifidiobacterium, Candida, Lactobacillus and Sterptomyces [15] [16] [17].

Effects of the implementation of probiotics on the poultry microbiome typically employ classical culture and classification methods. Notably, traditional culture methods are energy intensive and time consuming practices consisting of isolations that do not account for the presence of fastidious growing or nonculturable bacteria [18]. Further, the costs of selective media along with reagents for carbon utilization and enzyme production testing for classification of numerous bacterial isolates are high. In contrast, cultureless examination of the microbiome of host tissue specimens using pyrosequencing of $16 \mathrm{~S}$ rDNA is a method that directly detects bacterial communities and provides a means for an added metagenomics research approach [19]. Pyrosequencing using Roche nextgeneration sequencing (NGS) 454 technology, in particular, is comparatively thorough for $16 \mathrm{~S}$ rRNA gene analysis because of the relatively long sequence reads obtained (ca. $500 \mathrm{bp}$ ) compared to other high throughput sequencing technologies that average $100 \mathrm{bp}$. In addition to the length of reads, NGS tech- 
nologies provide more nucleotides to characterize from a given DNA sample when compared with conventional approaches [20].

Here, we compared microbe populations present in chick cecum following feeding probiotics consisting of Bacillus subtilis with those fed a normal diet (feed without probiotics). Additionally, litter microbiota present before and after composting the litter were analysed. Bacterial populations were classified based on $16 \mathrm{~S}$ rDNA sequencing analysis. An understanding of the development of the normal bacterial community provided a method to detect disruption in the flora and determine the effects of food animal management changes. The success and precise assessment of the bacterial information using high throughput pyrosequencing demonstrated in this study may allow for timely manipulation of the intestinal flora with the intention of enhancing intestinal health and feed conversion ratios.

\section{Materials and Methods}

\subsection{Probiotic Experiment}

Poultry Rearing. A total of 450 male broilers (Gallus domesticus) were obtained from the Cobb-Vantress hatchery, Inc (Timpson, Texas, USA) immediately after hatching (i.e. zero days of age). At the hatchery, birds were vaccinated for Marek's disease, Newcastle's disease and bronchitis using standard methods [21]. The broilers were divided among 28 floor pens $(1.2 \mathrm{~m} 1.2 \mathrm{~m})$ at the Stephen F. Austin State University (SFASU) Science Research Center, Nacogdoches, TX, USA with 15 birds per pen on fresh litter. The facility is environmentally controlled with negative pressure rooms (i.e. air expelled from the room). To provide the birds a relatively stable thermal environment, ventilation and heat ranged from $32^{\circ} \mathrm{C}$ daily to $21^{\circ} \mathrm{C}$ nightly. All birds received the same basal diet formulated according to the Nutrient Requirements of Chickens [22]. Clean water and feed were provided ad libitum throughout the study via Lubing Feather Soft Nipple Drinkers and then Tube Feeders (QC Supply, Schuyler, NE, USA).

Preparation of Inocula for Challenges. From glycerol stocks, $500 \mu \mathrm{L}$ a of Salmonella enterica poultry isolate was added to $30 \mathrm{~mL}$ of DifcoTM RappaportVassiliadis R10 (Becton, Dickinson and Company, Franklin Lakes, NJ, USA) broth amended with novobiocin at $25 \mu \mathrm{g} / \mathrm{mL}$ (Sigma, St. Louis, MO) and nalidixic acid at $20 \mu \mathrm{g} / \mathrm{mL}$ (Sigma, St. Louis, MO), and incubated for $16-18 \mathrm{~h}$ in an Innova 4300 shaker (New Brunswick, Edfield, CT, USA) at $37^{\circ} \mathrm{C}$ and $250 \mathrm{RPM}$. A Campylobacter jejuni poultry isolate was propagated by adding $500 \mu \mathrm{L}$ of a frozen glycerol stock to $30 \mathrm{~mL}$ of Bolton broth base (Sigma-Aldrich, St. Louis, MO) amended with novobiocin at $25 \mu \mathrm{g} / \mathrm{mL}$ (Sigma-Aldrich, St. Louis, MO) and nalidixic acid $\left(20 \mu \mathrm{g} / \mathrm{mL}\right.$, Sigma-Aldrich, St. Louis, MO) and incubated at $42^{\circ} \mathrm{C}$ for 16 - $18 \mathrm{~h}$ without any agitation in the presence of $10.0 \%$ carbon dioxide, $4.9 \%$ oxygen and $8 \%$ nitrogen obtained as a compressed gas (Gibson Laboratories, Lexington, KY, USA).

Following the incubation, $1 \mathrm{ml}$ of the $\mathrm{S}$. enterica culture was inoculated into $100 \mathrm{~mL}$ of fresh $\mathrm{R} 10$ broth contained in a $500 \mathrm{~mL}$ flask and incubated at $37^{\circ} \mathrm{C}$, 
$250 \mathrm{RPM}$ in Innova 4300 shaker incubator. Similarly, $1 \mathrm{ml}$ of $C$. jejuni was inoculated in a $50 \mathrm{~mL}$ conical tube containing Bolton broth and incubated at $42^{\circ} \mathrm{C}$ after the passage of compressed gas. Optical density of the culture was checked periodically until attaining an absorbance 0.45 at a wavelength of $625 \mathrm{~nm}$. Once the cultures entered log phase, the bacteria were pelleted by centrifugation at $12,000 \times \mathrm{g}$ for $5 \mathrm{~min}$. The supernatant was discarded and the cells were washed with sterile Phosphate Buffer Saline (PBS; $130 \mathrm{mM} \mathrm{NaCl}, 7 \mathrm{mM}$ Na2HPO4, 3 $\mathrm{mM} \mathrm{NaH} 2 \mathrm{PO} 4, \mathrm{pH} 7.3$ ) twice and then suspended in $40 \mathrm{~mL}$ of PBS for inoculations.

Final concentrations administered in the challenges were $3 \times 109$ colony forming units $(\mathrm{CFU}) / \mathrm{mL}$ for S.enterica and $1 \times 109 \mathrm{CFU} / \mathrm{mL}$ for C.jejuni. Birds were infected by oral gavage with S.enterica or C. jejuni in $0.2 \mathrm{~mL}$ of physiological saline $0.85 \% \mathrm{w} / \mathrm{v}$ on the 7 th and 39 th day of age as designated in Table 1. Control groups (Treatments 5 and 6) were provided PBS.

Caecum Samples. Previous studies by Barnes et al. (1972), and Wei et al. (2013) showed that a diverse microbiota was found primarily in the caecum. Therefore, this study focused on the ceca microbiome [23] [24]. Three days following each challenge, caecum samples $(n=56)$ were harvested (i.e. at the 10th day and 42nd). The cecal sacs were removed from two randomly selected birds per pen on the day of harvest. The caecum contents of both chicks from a pen were pooled for molecular analysis.

Genomic DNA Isolation. Caecum contents were aseptically scraped into sterile $50 \mathrm{~mL}$ tubes containing $10 \mathrm{~mL}$ of sterile PBS and mixed by vortexing for 3 min. Debris was removed by centrifugation at $700 \times \mathrm{g}$ for $1 \mathrm{~min}$. The supernatant was collected and centrifuged at $12,000 \times \mathrm{g}$ for $5 \mathrm{~min}$ to pellet bacteria that was then suspended in $2 \mathrm{~mL}$ PBS and centrifuged at $12,000 \times \mathrm{g}$ for $5 \mathrm{~min}$. The PBS wash was repeated and the pellet was finally suspended in $2 \mathrm{ml}$ PBS. Glycerol stocks were prepared by drawing $500 \mu \mathrm{L}$ of the washed cells and flash freezing in liquid nitrogen immediately after the addition of $1 \mathrm{~mL}$ glycerol. The remaining cells were stored at $-20^{\circ} \mathrm{C}$ for DNA extraction.

The bacterial genomic DNA was isolated using a Wizard Genomic DNA purification Kit (Promega Corporation, Madison, USA) as per the manufacturer's protocol. The DNA purity was checked spectrophotometrically using a Varian Cary $50 \mathrm{UV}$ - Vis spectrophotometer equipped with a Hellma microcell tray for microliter sample volumes (Hellma Analytics, Mullheim, Germany).

\subsection{Litter Compost Experiment}

Bird Rearing Facility. Between batches of birds the litter was composted to measure changes in the distribution of pathogenic bacteria. The broiler housing facility at the SFASU Poultry Center is temperature controlled with four tunnel-ventilations and a solid sidewall. The length and width of each house measured $152 \mathrm{~m} \times 13 \mathrm{~m}$ and was stocked with 27,900 newly hatched broiler chicks at a stocking density of $0.23 \mathrm{~m} 2 /$ bird. The two facilities used were designated as House 1 and House 2 each of which was partitioned into two with a composted 
Table 1. Poultry experiment with probiotic treatments. Effect of the Probiotic (Bacillus subtilis) on chick cecum microbial flora was determined after challenging birds with Salmonella enterica (S.e) serovar Enteritidis, Campylobacter jejuni (C.j), and appropriate controls. The experiment consisted of six treatments: Treatment 1 (S.e challenged and no Probiotic), Treatment 2 (S.e challenged + Probiotic), Treatment 3 (C.j challenged and no Probiotic), Treatment 4 (C.j challenged + Probiotic), Treatment 5 (no challenge + Probiotic) and Treatment 6 (no challenge and no probiotic).

\begin{tabular}{ccc}
\hline Treatment & Challenge \& Organism Used & Probiotic added \\
\hline $\mathbf{1}$ & Yes (S.e) & No \\
$\mathbf{1}$ & Yes (S.e) & No \\
$\mathbf{1}$ & Yes (S.e) & No \\
$\mathbf{1}$ & Yes (S.e) & No \\
$\mathbf{2}$ & Yes (S.e) & Yes \\
$\mathbf{2}$ & Yes (S.e) & Yes \\
$\mathbf{2}$ & Yes (S.e) & Yes \\
$\mathbf{2}$ & Yes (S.e) & Yes \\
$\mathbf{2}$ & Yes (S.e) & Yes \\
$\mathbf{3}$ & Yes (C.j) & No \\
$\mathbf{3}$ & Yes (C.j) & No \\
$\mathbf{3}$ & Yes (C.j) & No \\
$\mathbf{3}$ & Yes (C.j) & No \\
$\mathbf{3}$ & Yes (C.j) & No \\
$\mathbf{4}$ & Yes (C.j) & Yes \\
$\mathbf{4}$ & Yes (C.j) & Yes \\
$\mathbf{4}$ & Yes (C.j) & Yes \\
$\mathbf{4}$ & Yes (C.j) & Yes \\
$\mathbf{4}$ & Yes (C.j) & Yes \\
$\mathbf{5}$ & None & Yes \\
$\mathbf{5}$ & None & Yes \\
$\mathbf{5}$ & None & Nes \\
$\mathbf{6}$ & None & No \\
$\mathbf{6}$ & None & None \\
\hline
\end{tabular}

and non-composted litter section. Each flock was reared for 49 days to an average market weight of $2.4 \mathrm{~kg} / \mathrm{bird}$.

In-House Windrow Composting. Prior to the beginning of the study, both houses were depopulated. Recycled litter was used in order to have a higher population of microorganisms than new pine wood shavings. The shavings had been used as bedding for five previous flocks. Immediately after flock removal, the litter in one house was turned into two windrow composting piles that ran the length of the house using a hydraulic blade turned at a 45 degree angle. Litter windrows were left unturned for 7 days to allow composting. After 7 days, the litter was spread across the house and leveled prior to chick placement. This procedure was repeated at the completion of each consecutive flock. 
Litter Samplings. Each house (House 1 and House 2) was divided into four 38 $\mathrm{m}$ sections lengthwise. Using a $30 \mathrm{~cm}$ soil collection tube (Acorn Naturalists, Tustin, CA USA), six litter samples were collected per $38 \mathrm{~m}$ sections from each house. Samples were then pooled and homogenized to make four composted and four non-composted samples in sterile bags and stored at $-20^{\circ} \mathrm{C}$. The bacterial DNA from $2.5 \mathrm{~g}$ poultry litter was isolated using the ZR Soil microbe DNA midiprep kit (Zymoresearch, Irvine, USA) as per the manufacturer's protocol.

\subsection{Next-Generation Sequencing}

16S rDNA Synthesis. Extracted DNA from the poultry probiotic experiment and litter compost studies were used as templates to amplify $16 \mathrm{~S}$ rDNA sequences using the polymerase chain reaction (PCR) in a MyCycler (BioRad Laboratories, Inc., USA). Reactions were performed in a $50 \mu \mathrm{L}$ total volume with GoTaq Green Master Mix from Promega Corp. (Madison, USA). The forward primer 27F (5'-AGAGTTTGATCMTGGCTCAG-3') is a $16 \mathrm{~S}$ ribosomal DNA specific universal primer for prokaryotes that was previously employed by Lane et al. [25]. The universal reverse primer for prokaryotes called 519R (5'-GWATTACCGCGGCKGCTG-3') was used by Turner et al. [26].

All the primers including Multiplex Identifiers (MIDs) listed in Table 2 were purchased from Sigma Genosys (a division of Sigma Aldrich). Figure 1 provides an illustration of the strategy used to combine the bacterial $16 \mathrm{~S}$ ribosomal DNA primer set with the MIDs. The PCR conditions were the following: $97^{\circ} \mathrm{C}$ for 5 minutes; 40 cycles of $60^{\circ} \mathrm{C}$ for 1 minute, $72^{\circ} \mathrm{C}$ for 1 minute 20 seconds and $95^{\circ} \mathrm{C}$ for 30 seconds; followed by a $72^{\circ} \mathrm{C}$ for 5 minutes and hold at $4^{\circ} \mathrm{C}$. The PCR amplified product was analyzed using agarose gel electrophoresis.

Pyrosequencing Application. After quantification of DNA, equal amounts of purified PCR products were pooled for Roche emPCR amplification that was performed as per the manufacturer's protocol (454 Roche Life Sciences,

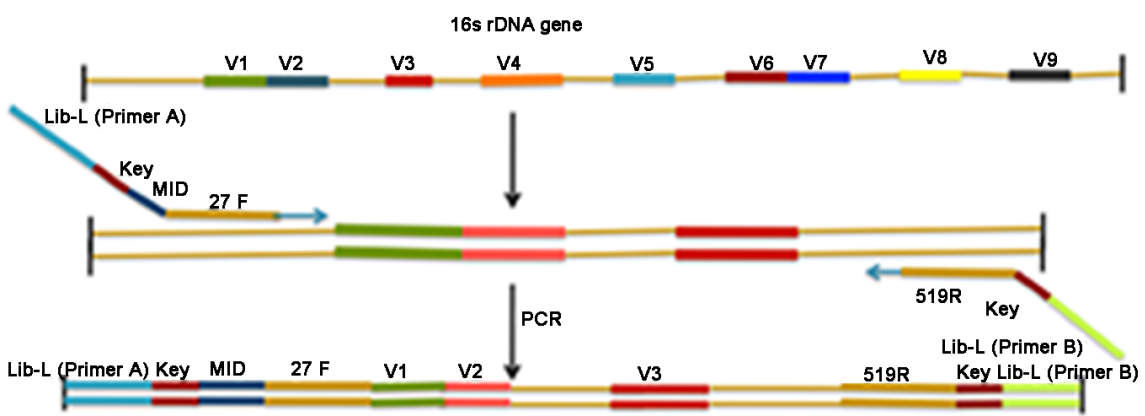

Figure 1. Schematic depiction of PCR primers used to amplify a 16S rDNA gene segment. The 16S rDNA gene includes a conserved region (thin line) and nine hypervariable regions (V1-V9). The primers were designed to target conserved regions and amplify variable sections with added Multiplex Identifiers (MIDs). The MID's were tagged to adaptors for sequencing using Roche $454 \mathrm{Lib}-\mathrm{L}$ Primer A: 5'-CCATCTCATCCCTGTCTCCGAC3', Lib-L Primer B: 5'-CCTATCCCCTGTGTGCCTTGGCAGTC-3', Sequencing key-TCAG, Universal Primer 27F: 5'-GRGTTTGATCMTGGCTAG, and the Universal Primer 519R: 5'-GTNTTACNGCGGCKGCTG-3'. 
Table 2. Degenerate primers used for bacterial $16 \mathrm{~S}$ rDNA amplification. Primers were designed with Roche 454 Lib-L forward primer (Primer A) at the 5' end, the sequencing key in the middle, and with a Multiplex Identifier (MID) and universal primer at the 3' end. The reverse primer with Roche 454 Lib-L (Primer B) and universal primer were positioned at the 3' end.

\begin{tabular}{|c|c|}
\hline Oligo Name & Sequence ( $\left.5^{\prime}-3^{\prime}\right)$ \\
\hline MID-1 & CCATCTCATCCCTGCGTGTCTCCGACTCAGACGAGTGCGTAGRGTTTGATCMTGGCTCAG \\
\hline MID-2 & CCATCTCATCCCTGCGTGTCTCCGACTCAGACGCTCGACAAGRGTTTGATCMTGGCTCAG \\
\hline MID-3 & CCATCTCATCCCTGCGTGTCTCCGACTCAGAGACGCGCTCAGRGTTTGATCMTGGCTCAG \\
\hline MID-4 & CCATCTCATCCCTGCGTGTCTCCGACTCAGAGCACTGTAGAGRGTTTGATCMTGGCTCAG \\
\hline MID-5 & CCATCTCATCCCTGCGTGTCTCCGACTCAGATCAGACACGAGRGTTTGATCMTGGCTCAG \\
\hline MID-6 & CCATCTCATCCCTGCGTGTCTCCGACTCAGATATCGCGAGAGRGTTTGATCMTGGCTCAG \\
\hline MID-7 & СCATCTCATCCCTGCGTGTCTCCGACTCAGCGTGTCTCTAAGRGTTTGATCMTGGCTCAG \\
\hline MID-8 & CCATCTCATCCCTGCGTGTCTCCGACTCAGCTCGCGTGTCANGRGTTTGATCMTGGCTCAG \\
\hline MID-10 & СCATCTCATCCCTGCGTGTCTCCGACTCAGTCTCTATGCGAGRGTTTGATCMTGGCTCAG \\
\hline MID-11 & CCATCTCATCCCTGCGTGTCTCCGACTCAGTGATACGTCTAGRGTTTGATCMTGGCTCAG \\
\hline MID-13 & CCATCTCATCCCTGCGTGTCTCCGACTCAGCATAGTAGTGAGRGTTTGATCMTGGCTCAG \\
\hline MID-14 & CCATCTCATCCCTGCGTGTCTCCGACTCAGCGAGAGATACAGRGTTTGATCMTGGCTCAG \\
\hline MID-15 & CCATCTCATCCCTGCGTGTCTCCGACTCAGATACGACGTAAGRGTTTGATCMTGGCTCAG \\
\hline MID-16 & CCATCTCATCCCTGCGTGTCTCCGACTCAGTCACGTACTAAGRGTTTGATCMTGGCTCAG \\
\hline MID-17 & CCATCTCATCCCTGCGTGTCTCCGACTCAGCGTCTAGTACAGRGTTTGATCMTGGCTCAG \\
\hline MID-18 & CCATCTCATCCCTGCGTGTCTCCGACTCAGTCTACGTAGCAGRGTTTGATCMTGGCTCAG \\
\hline MID-19 & CCATCTCATCCCTGCGTGTCTCCGACTCAGTGTACTACTCAGRGTTTGATCMTGGCTCAG \\
\hline MID-20 & CCATCTCATCCCTGCGTGTCTCCGACTCAGACGACTACAGAGRGTTTGATCMTGGCTCAG \\
\hline MID-21 & CCATCTCATCCCTGCGTGTCTCCGACTCAGCGTAGACTAGAGRGTTTGATCMTGGCTCAG \\
\hline MID-22 & CCATCTCATCCCTGCGTGTCTCCGACTCAGTACGAGTATGAGRGTTTGATCMTGGCTCAG \\
\hline MID-23 & CCATCTCATCCCTGCGTGTCTCCGACTCAGTACTCTCGTGAGRGTTTGATCMTGGCTCAG \\
\hline MID-24 & CCATCTCATCCCTGCGTGTCTCCGACTCAGTAGAGACGAGAGRGTTTGATCMTGGCTCAG \\
\hline MID-25 & CCATCTCATCCCTGCGTGTCTCCGACTCAGTCGTCGCTCGAGRGTTTGATCMTGGCTCAG \\
\hline MID-26 & CCATCTCATCCCTGCGTGTCTCCGACTCAGACATACGCGTAGRGTTTGATCMTGGCTCAG \\
\hline MID-27 & CCATCTCATCCCTGCGTGTCTCCGACTCAGACGCGAGTATAGRGTTTGATCMTGGCTCAG \\
\hline MID-28 & СCATCTCATCCCTGCGTGTCTCCGACTCAGACTACTATGTAGRGTTTGATCMTGGCTCAG \\
\hline MID-29 & CCATCTCATCCCTGCGTGTCTCCGACTCAGACTACTATGTAGRGTTTGATCMTGGCTCAG \\
\hline MID-30 & СCATCTCATCCCTGCGTGTCTCCGACTCAGACTACTATGTAGRGTTTGATCMTGGCTCAG \\
\hline $519 \mathrm{R}$ & СCTATCCCCTGTGTGCCTTGGCAGTCTCAGGTNTTACNGCGGGCKGCTG \\
\hline
\end{tabular}

Indianapolis, IN, USA). This method was followed for 10th day, 42nd day and litter samples separately. A Roche GS Junior System was used for pyrosequencing. The GS De Novo Assembler (Roche) was used to trim and group the data (i.e., adapter, linker and primer sequences) based on MID as well as generate 
consensus sequences of the DNA libraries. The assembled contigs were used in a metagenomic analysis with the CAMERA database [27] [28].

Statistical Analysis. Based upon the CAMERA BLASTn derived matches, the sequences were classified at the appropriate taxonomic levels based on Data Analysis Methodology offered by the Research and Testing Laboratory, Lubbock, TX, USA (http://rtlgenomics.com/). Additionally, RDP Naïve Bayesian rDNA classifier version 2.5 was used to organize the data into taxonomy groups with a bootstrap cutoff of $80 \%$ (https://rdp.cme.msu.edu/). Two-Way ANOVA was used with GraphPad Prism version 6.0.

(https://www.graphpad.com/scientific-software/prism/), in order to further analyze the data and calculate the variance to observe the effect of treatments on the chick's microbiome. A p-value $<0.05$ was considered statistically significant. The SAS based program JMP Genomics Version 5.1 was employed to organize the distribution of identified bacteria [29].

\section{Results}

\subsection{Probiotic Poultry Experiment}

Results of the 454 sequencing experiments performed on the samples collected on day 10 and 42 showed that the primers designed with the MIDs successfully amplified specific 16S rDNA regions of multiple bacteria. Pyrosequencing generated 19.8 $\mathrm{Mbp}$ with average reads of $389 \mathrm{bp}$ and $43.7 \mathrm{Mbp}$ with average reads of $342 \mathrm{bp}$ for the pooled chick caecum samples from the $10^{\text {th }}$ and $42^{\text {nd }}$ day collection periods, respectively.

The CAMERA BLASTn analysis using the collective data produced over 20,000 significant matches for all of the treatment samples (Table 3). The TwoWay ANOVA analysis using both the $10^{\text {th }}$ and $42^{\text {nd }}$ day samples from treatments

Table 3. Distribution of bacteria identified based on $16 \mathrm{~S}$ ribosomal DNA sequence analysis from the caeca of chicks that had been provided a probiotic and challenged with either Salmonella enterica (S.e) serovar Enteriditis or Campylobacter jejuni (C.j), and appropriate controls. The experiment consisted of six treatments: Treatment 1 (S.e challenged and no Probiotic), Treatment 2 (S.e challenged + probiotic), Treatment 3 (C.j challenged and no Probiotic), Treatment 4 (C.j challenged + Probiotic), Treatment 5 (no challenge + Probiotic) and Treatment 6 (no challenge and no probiotic). Genomic DNA was extracted from poultry caeca at the $10^{\text {th }}$ and $42^{\text {nd }}$ day following each Treatment.

\begin{tabular}{ccccccc}
\hline Treatment & \multicolumn{2}{c}{ Unique Bacterial Classified } & \multicolumn{2}{c}{ Taxonomic Bacterial Groups } \\
\hline & 10 Day & 42 Day & Total & 10 Day & 42 Day & Total \\
\hline $\mathbf{1}$ & 609 & 3444 & 4053 & 132 & 409 & 541 \\
3 & 1097 & 1902 & 2999 & 249 & 307 & 556 \\
$\mathbf{4}$ & 1699 & 1974 & 3673 & 361 & 300 & 661 \\
$\mathbf{5}$ & 34 & 1631 & 1665 & 5 & 226 & 231 \\
$\mathbf{6}$ & 1468 & 2871 & 4339 & 332 & 390 & 722 \\
\hline
\end{tabular}


that included exposure to $S$. enterica or $C$. jejuni along with the probiotic revealed a difference in the number of genera with respect to collection period. However, the probiotic treatment did not provide statistical evidence for a reduction in pathogens detected $(\mathrm{p}=0.1751)$. Overall, Firmicutes were predominant in both days sampled from the six phyla identified (Figure 2(a)). Further, increased levels of beneficial genera such as Blautia, Eubacteria, Faecalibacteria, among others were detected from the $10^{\text {th }}$ to the $42^{\text {nd }}$ sample collections (Figure 2(b)). Clostridia that includes both pathogenic and non-pathogenic species were unaffected by treatment with or without the probiotic. Bacillus spp. were detected in all of the treatment samples (Figure 2(d)). A total of 6923 and 14,448 bacterial strains were identified for the $10^{\text {th }}$ and $42^{\text {nd }}$ day samples, respectively. Figures 3-8 illustrate the distributions of the identified bacteria that comprised $>1.5 \%$ of the population. However, the number of genera decreased as time increased irrespective of the treatment with or without the probiotic for both beneficial (Figure 2(b)) and pathogenic bacteria (Figure 2(c)). As Bacillus spp. are ubiquitous, expectantly they were detected in the entire sample analyzed (Figure 2(d)).

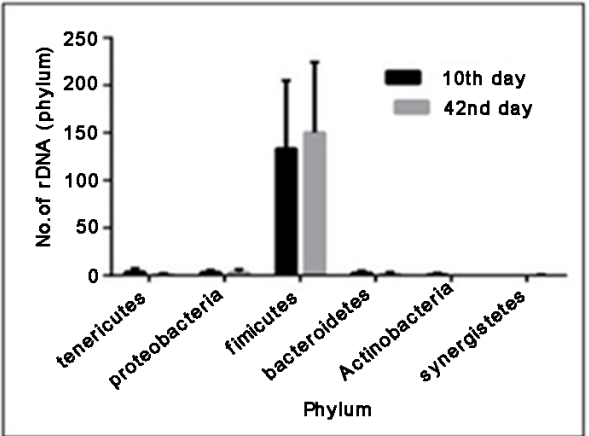

(a)

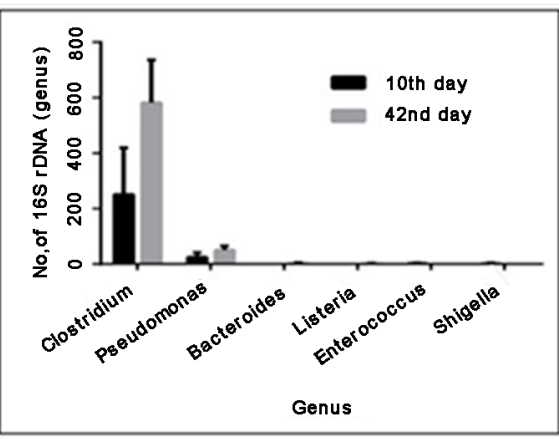

(c)

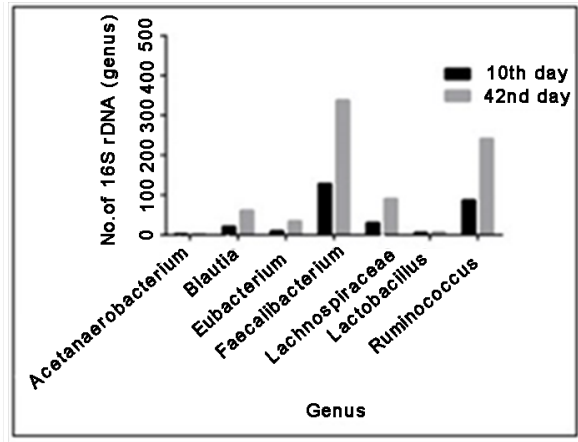

(b)

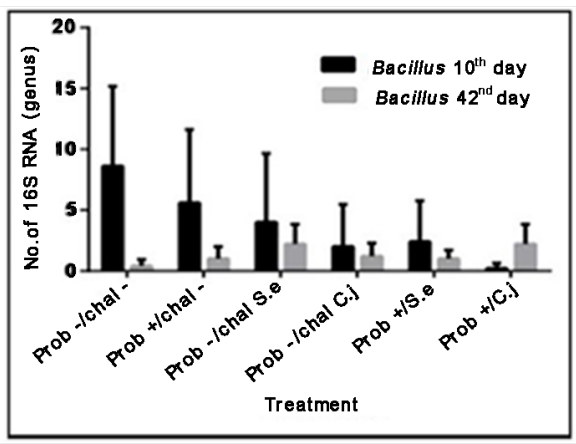

(d)

Figure 2. Two-way ANOVA providing the distribution of significant $(\mathrm{p}<0.05)$ phyla and genera based on $16 \mathrm{~S}$ rDNA sequence analysis. Genomic DNA was extracted from poultry caeca at the $10^{\text {th }}$ and $42^{\text {nd }}$ day following a challenge $\left(\mathrm{Chal}^{+}\right)$or no challenge $\left(\mathrm{Chal}^{-}\right)$with a bacterial pathogen (Salmonella enterica-S.e or Campylobacter jejuni-C.j), and/or probiotic (Bacillus subtilis) administration. Figure (a) illustrates the phylum distribution. Figure (b) illustrates beneficial bacterial genera identified. Figure (c) illustrates pathogenic genera representatives. Figure (d) illustrates the detection of Bacillus spp. without administration of the probiotic $\left(\mathrm{Prob}^{-}\right)$or following the probiotic treatment $\left(\mathrm{Prob}^{+}\right)$. 


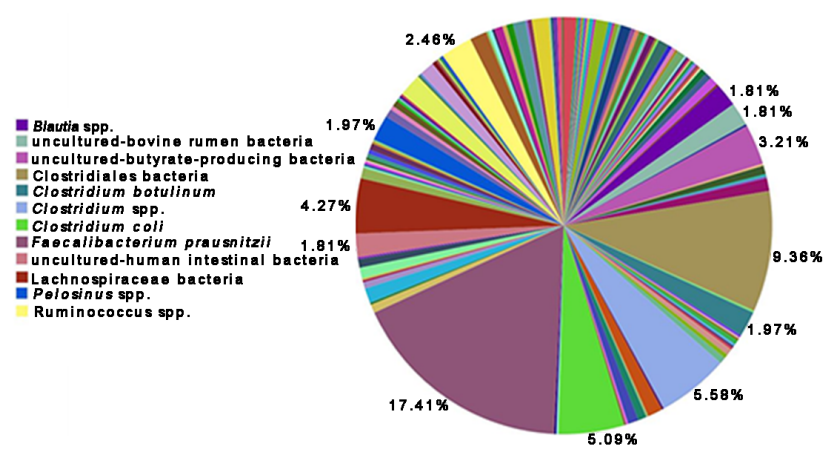

(a)

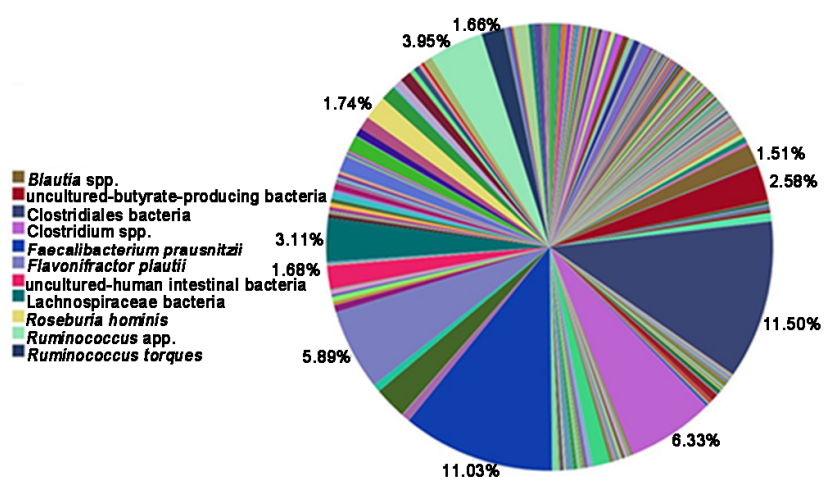

(b)

Figure 3. Distribution of bacteria identified based on $16 \mathrm{~S}$ ribosomal DNA sequence analysis from caeca of chicks that had been challenged with Salmonella enterica and not administered a probiotic. Genomic DNA was extracted from poultry caeca at the $10^{\text {th }}$ (Pie (a)) and $42^{\text {nd }}($ Pie (b)) day following the treatment.

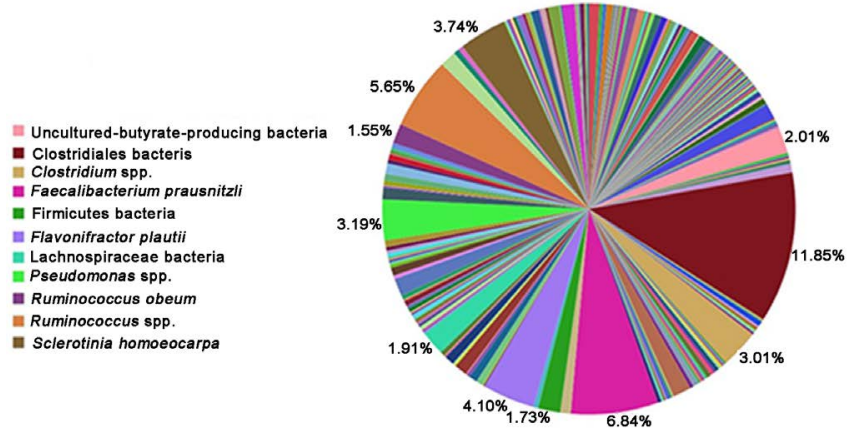

(a)

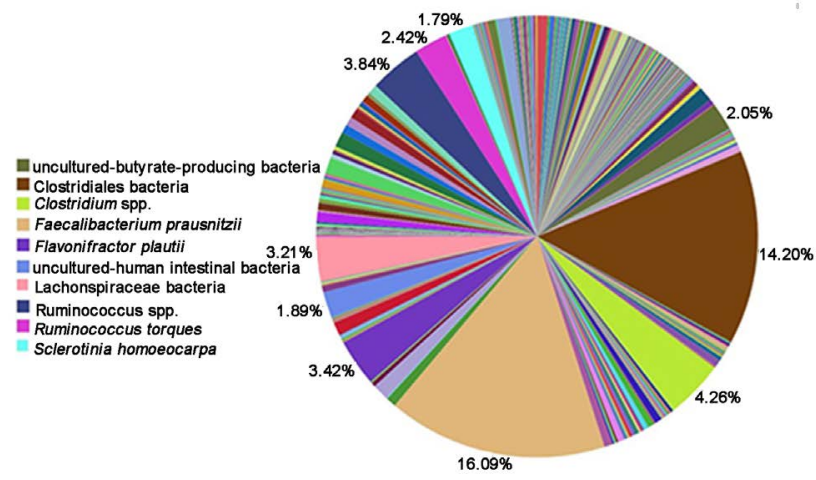

(b)

Figure 4. Distribution of bacteria identified based on $16 \mathrm{~S}$ ribosomal DNA sequence analysis from caeca of chicks that had been challenged with Salmonella enterica and administered a probiotic. Genomic DNA was extracted from poultry caeca at the $10^{\text {th }}$ (Pie (a)) and $42^{\text {nd }}($ Pie (b)) day following the treatment.

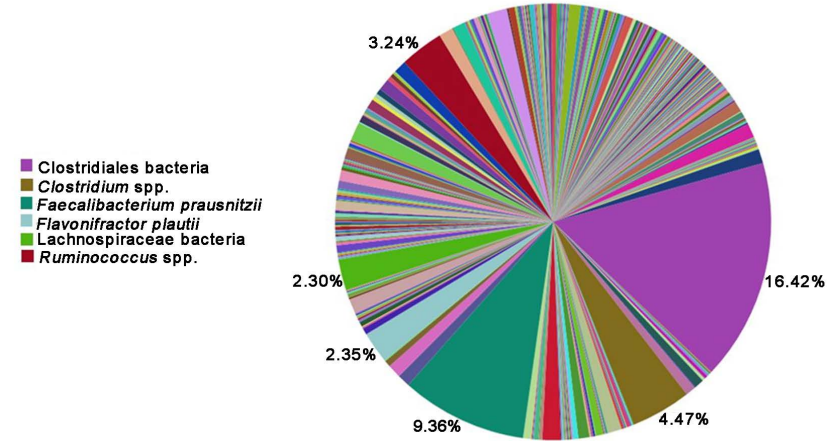

(a)

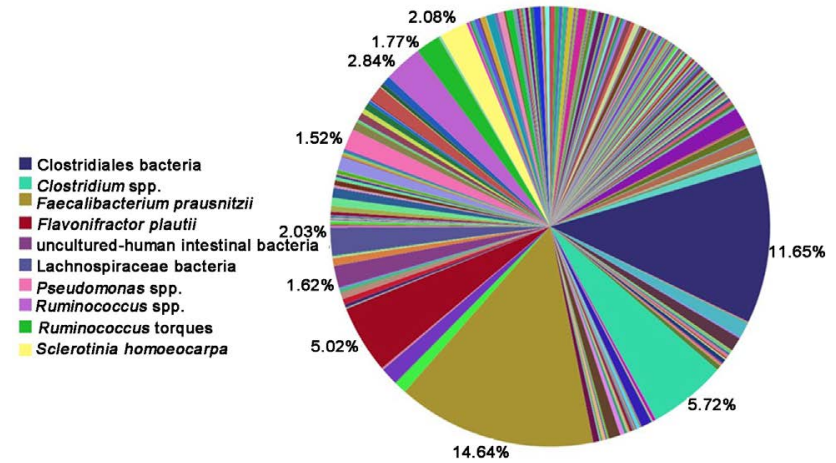

(b)

Figure 5. Distribution of bacteria identified based on $16 \mathrm{~S}$ ribosomal DNA sequence analysis from caeca of chicks that had been challenged with Campylobacter jejuni and not administered a probiotic. Genomic DNA was extracted from poultry caeca at the $10^{\text {th }}\left(\right.$ Pie (a)) and $42^{\text {nd }}($ Pie (b)) day following the treatment.

\subsection{Litter Compost Analysis}

Pyrosequencing data generated 4.4 Mbp with an average read length of $412 \mathrm{bp}$ for the pooled DNA extracted from the litter samples. The RDP database 


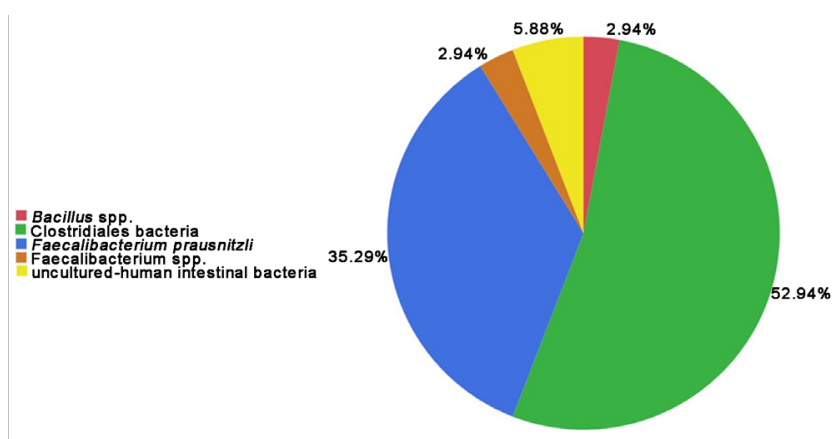

(a)

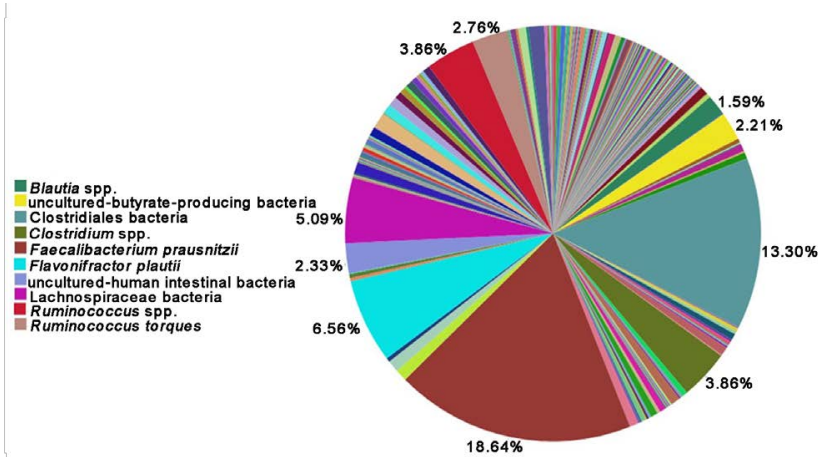

(b)

Figure 6. Distribution of bacteria identified based on 16S ribosomal DNA sequence analysis from caeca of chicks that had been challenged Campylobacter jejuni and administered a probiotic. Genomic DNA was extracted from poultry caeca at the $10^{\text {th }}(\mathrm{Pie}$ (a)) and $42^{\text {nd }}($ Pie (b)) day following the treatment.

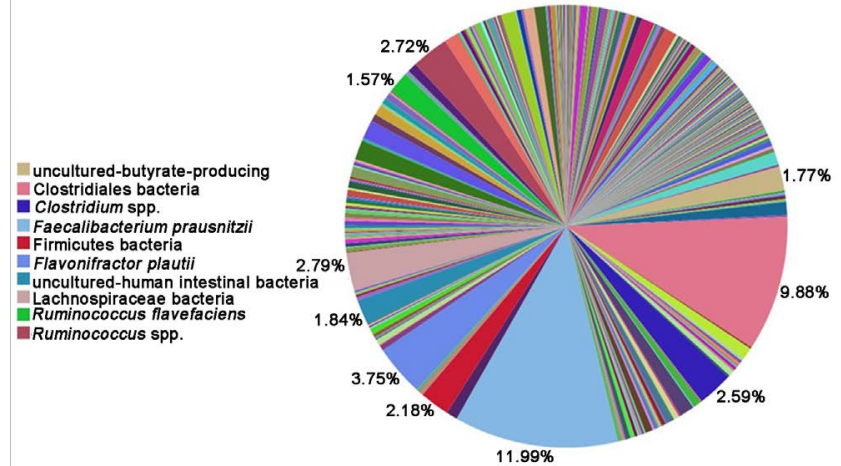

(a)

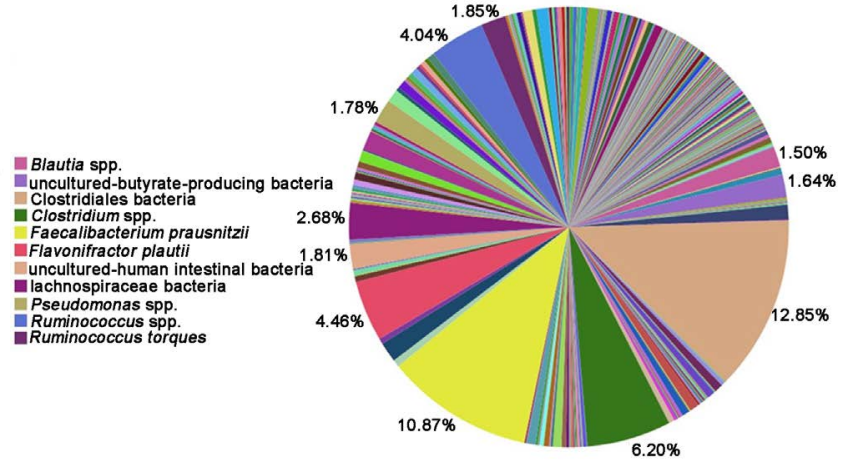

(b)

Figure 7. Distribution of bacteria identified based on 16S ribosomal DNA sequence analysis from caeca of chicks that had not been challenged with a bacterial pathogen and administered a probiotic. Genomic DNA was extracted from poultry caeca at the $10^{\text {th }}$ (Pie (a)) and $42^{\text {nd }}($ Pie (b)) day following the treatment.

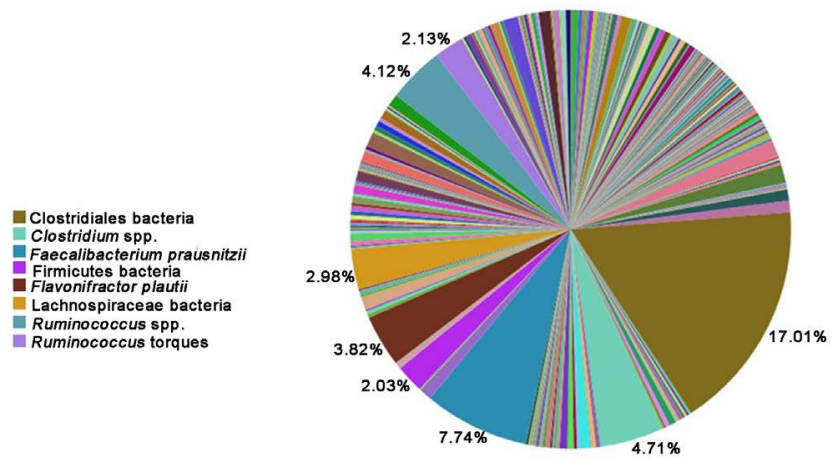

(a)

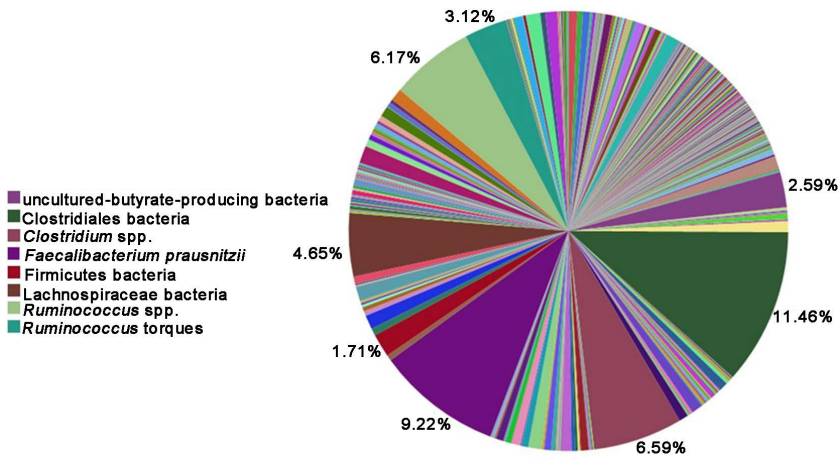

(b)

Figure 8. Distribution of bacteria identified based on $16 \mathrm{~S}$ ribosomal DNA sequence analysis from caeca of chicks that had not been challenged with a bacterial pathogen and not administered a probiotic. Genomic DNA was extracted from poultry caeca at the $10^{\text {th }}$ (Pie (a)) and $42^{\text {nd }}$ (Pie (b)) day following the mock a challenge with a bacterial pathogen and no probiotic administration.

classification identified six phyla from the broiler litter with a majority consisting of Firmicutes and Actinobacteria at the two housing units (Table 4). Staphylococcus and Salinicoccus were the predominant Firmicutes genera detected 
irrespective of the treatments (Figure 9). Comparisons of genera from the phylum Actinobacteria showed that Bracybacterium was predominant in broiler litter irrespective of the treatments (Figure 10).

\section{Discussion}

The current study was intended to determine the proof of concept that nextgeneration sequencing technology could be applied to rapidly and efficiently

Table 4. Two poultry rearing facilities partitioned to house poultry pens (House $1-\mathrm{H} 1$ ) and House 2 - H2) that were bedded with either non-composted or composted wood shavings to assess prokaryotic composition differences between the litter. Extractions of DNA from litter samples were used to detect bacterial phyla composition based on 16S rDNA bacterial sequence analysis by employing the Ribosomal Database Project-Naive Bayesian rDNA classifier version 2.5 (https://rdp.cme.msu.edu/).

\begin{tabular}{ccccc}
\hline Phylum & $\begin{array}{c}\text { Non-Compost } \\
\text { H1 }\end{array}$ & $\begin{array}{c}\text { Compost } \\
\text { H1 }\end{array}$ & Non-Compost & \multicolumn{2}{c}{ Compost } \\
\hline Actinobacteria & 4807 & 4380 & H2 & 62 \\
Bacteroidetes & 24 & 103 & 78 & 0 \\
Cyanobacteria & 1 & 5 & 0 & 0 \\
Firmicutes & 6914 & 8013 & 125 & 120 \\
Proteobacteria & 10 & 24 & 2 & 2 \\
Tenericutes & 4 & 3 & 0 & 0 \\
\hline
\end{tabular}

(a)

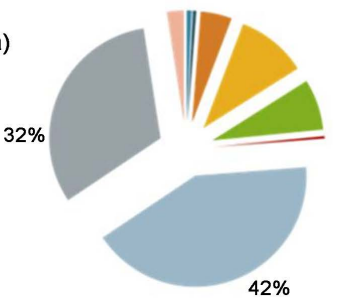

(c)

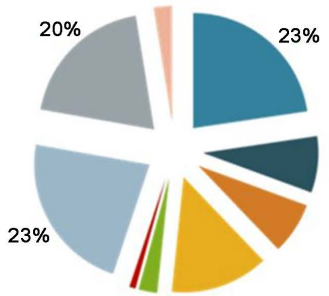

(b)

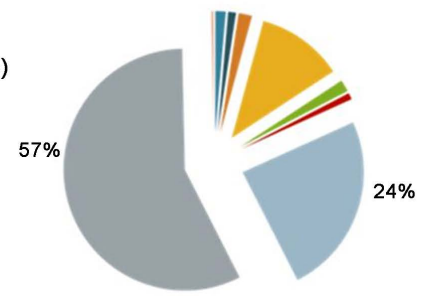

(d)

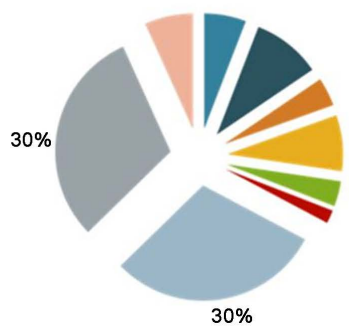

Clostridium

Faecalibacterium

Jeotgalicoccus

- Lactobacillus

Oceanobacillus

Oscillospira

Salinicoccus

- Staphylococcus

Virgibacillus

Figure 9. Distribution of genera from the phylum Actinobacteria detected in composted and non-composted poultry litter. Extractions of DNA from litter samples were used to determine bacterial phyla composition based on $16 \mathrm{~S}$ rDNA bacterial sequence analysis by employing the Ribosomal Database Project (RDP) - Naive Bayesian rDNA classifier version 2.5 (https://rdp.cme.msu.edu/). Classifications from the RDP analysis of the sequences had an $80 \%$ cutoff. Charts (a) and (b) illustrate the 1st set of non-composted and composted litter genera. Charts (c) and (d) illustrate the 2nd set non-composted and composted litter genera. 


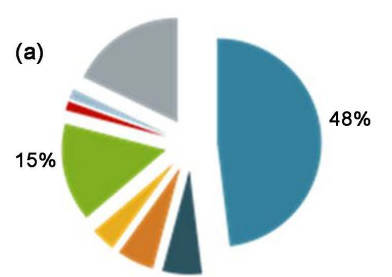

(c)

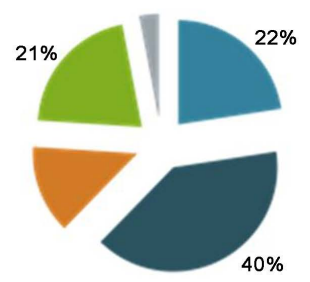

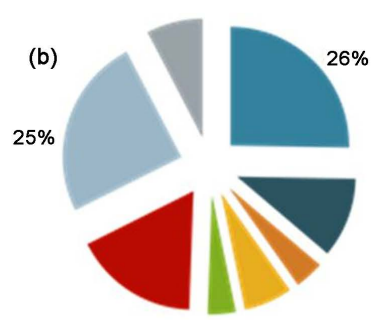

(d)

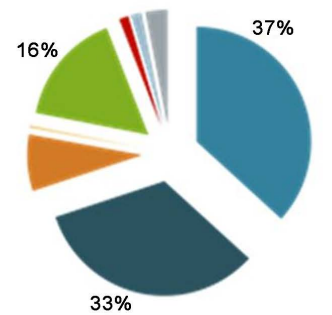

Brachybacterium

Brevibacterium

Corynebacterium

- Georgenia

Nocardiopsis

- Saccharomonospora

Saccharopolyspora

Yaniella

Figure 10. Distribution of genera from the phylum Firmicutes detected in composted and non-composted poultry litter. Extractions of DNA from litter samples were used to determine bacterial phyla composition based on 16S rDNA bacterial sequence analysis by employing the Ribosomal Database Project (RDP)—Naive Bayesian rDNA classifier version 2.5 (https://rdp.cme.msu.edu/). Classifications from the RDP analysis of the sequences had an $80 \%$ cutoff. Charts (a) and (b) illustrate the 1st set of non-composted and composted litter genera. Charts (c) and (d) illustrate the 2nd set non-composted and composted litter genera.

assess the cecal microbiome of poultry treated with a probiotic. The MIDs provided a manner to pool samples for cost savings and sequencing efficiency yet differentiate between the sample sources. Effects of probiotic administration on the chick microbiome, specifically on two known pathogenic bacteria $S$. enterica and $C$. jejuni were the basis of the measurements. Additionally, the effect of windrow composting on microbial populations in reused poultry litter was also examined. Pyrosequencing results of pooled samples that reduced cost and processing time showed that the chick microbiome and poultry litter consists of numerous varieties of bacteria.

In accordance with previous work [30] [31], Firmicutes were the predominant phylum identified. Representatives of Lachnospiraceae and Ruminococcaceae families were also detected as reported by Danzeisen et al. [32]. At genus level, the overall number of $16 \mathrm{~S}$ rDNA sequence matches decreased from the first to second time interval sampled.

The probiotic employed in this study was found to not significantly reduce putative pathogen levels in the microbiome of the chick caecum. Though the chicks were challenged with $S$. enterica and $C$. jejuni, no significant difference was observed in their populations at day 10 or day 42 with or without the probiotic. A possible explanation could be that study was conducted in an academic setting in contrast to an actual poultry production facility [32].

Here, as in general poultry industry protocol, we used recycled wood shavings as bedding material with a comparable ventilation system. Other work has con- 
sidered possible alternatives to litter to examine the diversity of microbial communities. For example, Kim et al. [33], working on pigs showed that animalto-animal variation could be negligible in genetically similar production animals where environment plays a critical role in determining animal gut microbiome. Kasier et al. [34] reported that colonization of $S$. enterica occurred on day seven post challenge. Interestingly, Wisner et al. [35], showed that the Salmonella was cleared after 3 and 4 days of post challenge which suggests that testing the feces could have helped in finding specific inoculated bacteria.

The poultry litter microbiota analysis showed an increased bacterial diversity in the poultry litter at the genus and species level after windrow composting (440 genera and 1700 species). Interestingly at the phylum level, (Table 4) reduced levels of Firmicutes, Proteobacteria and Tenericutes that constitute the majority of known pathogenic bacteria were measured. By the use of the RDP database, Firmicutes were the predominant phylum identified in reused litter irrespective of the treatments. Cressman et al. [36], showed that the pathogenic bacteria such as Campylobacter, Salmonella, Listeria and Yersinia species were not detectable by using traditional PCR platform screens. In contrast, the pyrosequencing method detected these pathogenic genera. Chlortetracycline-resistant bacteria and tylosin-resistant bacteria were also observed in reused poultry litter that might enter birds' gut that fed on this litter thus causing resistance to antibiotics. Staphylococcus and Clostridia were found to be the predominant genera in reused litter.

\section{Conclusions}

The results of this study showed that pyrosequencing is both a sensitive and powerful tool to study the microbiome of chicks after treatments in poultry management aimed to minimize downstream contamination. Also, the study showed that multiple samples can be sequenced simultaneously using MID's thus, demonstrating that next-generation sequencing is an economical platform in combination with freely available bioinformatic database tools for chick microbiome analysis. Additionally, the computational analysis provided a mechanism to identify novel and uncommon genera. There were over 400 genera and 800 species identified from the different treatments. Results from this study suggested that neither of the treatments (probiotic administration or in-house windrow composting) had caused significant reductions of pathogenic bacteria.

This is the first study to employ next-generation sequencing technology to analyze the effects of a specific probiotic administrated on the microbiome of broiler chicks. Results of the study indicated that neither addition of this particular probiotic nor administration of the composting schemes provided a decrease in pathogen presence. Nevertheless, the study helped in identifying drawbacks of probiotic and litter treatments that could be modified in future studies for optimum pathogen control. Results from this work demonstrated that high throughput next-generation pyrosequencing technology is a cost effective method to streamline the effectiveness of potential biological strategies to minimize the occurrence of animal pathogens in poultry. 


\section{Acknowledgements}

Michael Hume kindly provided the Salmonella and Campylobacter isolates. Scott Dowd generously contributed critical insight to the litter work. Thanks are due to Richard Hernandez for editorial support.

\section{References}

[1] Henry, R. and Rothwell, G. (1995) The World Poultry Industry, IFC Global Agribusiness Series, World Bank, Washington DC. https://doi.org/10.1596/0-8213-3429-8

[2] United States Department of Agriculture, Economic Research Service (2005) US and State Farm Cash Receipts 1924-2004. United States Department of Agriculture, Economic Research Service, Washington DC.

[3] Wolfe, N.D., Dunavan, C.P. and Diamond, J. (2007) Origins of Major Human Infectious Diseases. Nature, 447, 279-283. https://doi.org/10.1038/nature05775

[4] Tauxe, R.V. (1992) Epidemiology of Campylobacter jejuni Infection in the United States and Other Industrialized Nations. In: Nachamkin, I., Blaser, M.J. and Tompkins, L.S., Eds., Campylobacter jejuni: Current Status and Future Trends, American Association of Microbiologists, Washington DC, 9-19.

[5] Skirrow, M.B. (1998) Campylobacteriosis. In: Palmer, S.R., Soulsby, S.R.L. and Simpson, D.I.H., Eds., Zoonoses, Oxford University Press, New York, 37-46.

[6] Corry, J.E.L. and Atabay, H.I. (2001) Poultry as a Source of Campylobacter and Related Organisms. Journal of Applied Microbiology, 90, 96S-114S. https://doi.org/10.1046/j.1365-2672.2001.01358.x

[7] Majowicz, S.E., Musto, J., Scallan, E., Angulo, F.J., Kirk, M., O’Brien, S.J., Jones, T.F., Fazil, A. and Hoekstra, R.M. (2010) The Global Burden of Nontyphoidal Salmonella gastroenteritis. Clinical Infectious Diseases, 50, 882-889. https://doi.org/10.1086/650733

[8] Silva, J., Leite, D., Fernandes, M., Mena, C., Gibbs, P.A. and Teixeira, P. (2011) Campylobacter Spp. As a Foodborne Pathogen: A Review. Frontiers in Microbiolo$g y, 2,200$. https://doi.org/10.3389/fmicb.2011.00200

[9] Wegener, H.C., Aarestrup, F.M., Jensen, L.B., Hammerum, A.M. and Bager, F. (1999) Use of Antimicrobial Growth Promoters in Food Animals and Enterococcus faecium Resistance to Therapeutic Antimicrobial Drugs in Europe. Emerging Infectious Diseases, 5, 329-335.

[10] Hakanen, A.J., Lehtopolku, M., Siitonen, A., Huovinen, P. and Kotilainen, P. (2003) Multidrug Resistance in Campylobacter jejuni Strains Collected from Finnish Patients During 1995-2000. Journal of Antimicrobial Chemotherapy, 52, 1035-1039. https://doi.org/10.1093/jac/dkg489

[11] Engberg, J., Neimann, J., Nielsen, E.M., Aarestrup, F.M. and Fussing, V. (2004) Quinolone-Resistant Campylobacter Infections in Denmark: Risk Factors and Clinical Consequences. Emerging Infectious Diseases, 10, 1056-1063.

https://doi.org/10.3201/eid1006.030669

[12] Diarra, M.S., Delaquis, P., Rempel, H., Bach, S., Harlton, C. and Aslam, M. (2014) Antibiotic Resistance and Diversity of Salmonella enterica Serovars Associated with Broiler Chickens. Journal of Food Protection, 77, 40-49. https://doi.org/10.4315/0362-028.JFP-13-251

[13] O’Toole, P.W. and Cooney, J.C. (2008) Probiotic Bacteria Influence the Composition and Function of the Intestinal Microbiota. Interdisciplinary Perspectives on Infectious Diseases, 2008, Article ID: 175285. https://doi.org/10.1155/2008/175285 
[14] Kabir, S.M.L. (2009) The Role of Probiotics in the Poultry Industry. International Journal of Molecular Sciences, 10, 3531-3546. https://doi.org/10.3390/ijms10083531

[15] Islam, M.W., Rahman, M.M., Kabir, S.M.L., Kamruzzaman, S.M. and Islam, M.N. (2004) Effects of Probiotics Supplementation on Growth Performance and Certain Haematobiochemical Parameters in Broiler Chickens. Bangladesh Journal of Veterinary Medicine, 2, 39-43.

[16] Willis, W.L., Isikhuemhen, O.S. and Ibrahim, S.A. (2007) Performance Assessment of Broiler Chickens Given Mushroom Extract Alone or in Combination with Probiotics. Poultry Science, 86, 1856-1860. https://doi.org/10.1093/ps/86.9.1856

[17] Apata, D.F. (2008) Growth Performance, Nutrient Digestibility and Immune Response of Broiler Chicks Fed Diets Supplemented with a Culture of Lactobacillus bulgaricus. Journal of the Science of Food and Agriculture, 88, 1253-1258. https://doi.org/10.1002/jsfa.3214

[18] Weisburg, W.G., Barns, S.M., Pelletier, D.A. and Lane, D.J. (1991) 16S Ribosomal DNA Amplification for Phylogenetic Study. Journal of Bacteriology, 173, 697-703.

[19] Zhu, X.Y., Zhong, T., Pandya, Y. and Joerger, R.D. (2002) 16S rRNA-Based Analysis of Microbiota from the Cecum of Broiler Chickens. Applied and Environmental Microbiology, 68, 124-137. https://doi.org/10.1128/AEM.68.1.124-137.2002

[20] Metzker, M.L. (2010) Sequencing Technologies-The Next Generation. Nature Reviews Genetics, 11, 31-46. https://doi.org/10.1038/nrg2626

[21] Rahaus, M., Augustinski, K., Castells, M. and Desloges, N. (2013) Application of a New Bivalent Marek's Disease Vaccine Does Not Interfere with Infectious Bronchitis or Newcastle Disease Vaccinations and Proves Efficacious. Avian Diseases, 57, 498-502. https://doi.org/10.1637/10334-082712-Reg.1

[22] NRC (1994) Nutrient Requirements of Poultry. 9th Revised Edition, National Academy Press, Washington DC.

[23] Barnes, E.M., Mead, G.C., Barnum, D.A. and Harry, E.G. (1972) The Intestinal Flora of the Chicken in the Period 2 to 6 Weeks of Age, with Particular Reference to the Anaerobic Bacteria. British Poultry Science, 13, 311-326. https://doi.org/10.1080/00071667208415953

[24] Wei, S., Morrison, M. and Yu, Z. (2013) Bacterial Census of Poultry Intestinal Microbiome. Poultry Science, 92, 671-683. https://doi.org/10.3382/ps.2012-02822

[25] Lane, D.J. (1991) 16S/23S rRNA Sequencing. In: Stackebrandt, E. and Goodfellow, M., Eds., Nucleic Acid Techniques in Bacterial Systematics, John Wiley \& Sons, New York, 115-175.

[26] Turner, S., Pryer, K.M., Miao, V.P.W. and Palmer, J.D. (1999) Investigating Deep Phylogenetic Relationships among Cyanobacteria and Plastids by Small Subunit rRNA Sequence Analysis. Journal of Eukaryotic Microbiology, 46, 327-338. https://doi.org/10.1111/j.1550-7408.1999.tb04612.x

[27] Sun, Q., Liu, L., Wu, L., Li, W., Liu, Q., Zhang, J. and Ma, J. (2015) Web Resources for Microbial Data. Genomics, Proteomics \& Bioinformatics, 13, 69-72. https://doi.org/10.1016/j.gpb.2015.01.008

[28] Dudhagara, P., Bhavsar, S., Bhagat, C., Ghelani, A., Bhatt, S. and Patel, R. (2015) Web Resources for Metagenomics Studies. Genomics, Proteomics \& Bioinformatics, 13, 296-303. https://doi.org/10.1016/j.gpb.2015.10.003

[29] JMP Version 5.1. (2011) SAS Institute Inc., Cary, NC, USA.

[30] Lu, J., Idris, U, Harmon, B., Hofacre, C. and Maurer, J.J. (2003) Diversity and Succession of the Intestinal Bacterial Community of the Maturing Broiler Chicken. Applied and Environmental Microbiology, 69, 6816-6824. 
https://doi.org/10.1128/AEM.69.11.6816-6824.2003

[31] Jozefiak, D., Rutkowski, A., Kaczmarek, S., Jensen, B.B. and Engberg, R.M. (2010) Effect of Beta-Glucanase and Xylanase Supplementation of Barley and Rye-Based Diets on Caecal Microbiota of Broiler Chickens. British Poultry Science, 51, 546 557. https://doi.org/10.1080/00071668.2010.507243

[32] Danzeisen, J.L., Kim, H.B., Isaacson, R.E., Tu, Z.J. and Johnson, T.J. (2011) Modulations of the Chicken Cecal Microbiome and Metagenome in Response to Anticoccidial and Growth Promoter Treatment. PLoS ONE, 6, e27949.

https://doi.org/10.1371/journal.pone.0027949

[33] Kim, M., Morrison, M. and Yu, Z. (2011) Status of the Phylogenetic Diversity Census of Ruminal Microbiomes. FEMS Microbiology Ecology, 76, 49-63. https://doi.org/10.1111/j.1574-6941.2010.01029.x

[34] Kaiser, P., Howell, J., Fife, M., Sadeyen, J.R., Salmon, N. and Rothwell, L. (2009) Towards the Selection of Chickens Resistant to Salmonella and Campylobacter Infections. Bulletin et Mémoires de I Académie Royale de Médecine de Belgique, 164, 17-25.

[35] Wisner, A.L., Desin, T.S., Koch, B., Lam, P.K., Berberov, E.M., Mickael, C.S., Potter, A.A. and Koster, W. (2010) Salmonella enterica Subspecies enterica serovar Enteritidis Salmonella Pathogenicity Island 2 Type III Secretion System: Role in Intestinal Colonization of Chickens and Systemic Spread. Microbiology, 156, 2770-2781. https://doi.org/10.1099/mic.0.038018-0

[36] Cressman, M.D., Yu, Z., Nelson, M.C., Moeller, S.J., Lilburn, M.S. and Zerby, H.N. (2010) Interrelations between the Microbiotas in the Litter and in the Intestines of Commercial Broiler Chickens. Applied and Environmental Microbiology, 76, 6572 6582 .

\section{Submit or recommend next manuscript to SCIRP and we will provide best service for you:}

Accepting pre-submission inquiries through Email, Facebook, LinkedIn, Twitter, etc. A wide selection of journals (inclusive of 9 subjects, more than 200 journals)

Providing 24-hour high-quality service

User-friendly online submission system

Fair and swift peer-review system

Efficient typesetting and proofreading procedure

Display of the result of downloads and visits, as well as the number of cited articles

Maximum dissemination of your research work

Submit your manuscript at: http://papersubmission.scirp.org/

Orcontact as@scirp.org 